\title{
Selection of Fertilizer and Cultivar of Sweet Pepper and Eggplant for Hydroponic Production
}

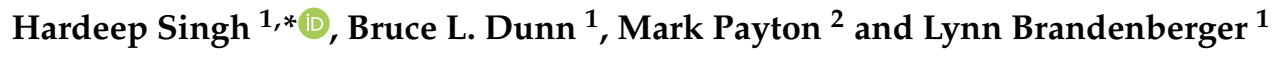 \\ 1 Department of Horticulture and Landscape Architecture, Oklahoma State University, \\ Stillwater, OK 74078-6027, USA \\ 2 Department of Statistics, Oklahoma State University, Stillwater, OK 74078-6027, USA \\ * Correspondence: hardeep.singh@okstate.edu
}

Received: 6 July 2019; Accepted: 5 August 2019; Published: 7 August 2019

\begin{abstract}
Dutch bucket hydroponic trials were conducted with the aim to evaluate the effects of different hydroponic fertilizers (5N-4.8P-21.6K, 5N-5.2P-21.6K, and 7N-3.9P-4.1K) on growth, fruit production, and the fruit quality (fruit shape index) parameters of two cultivars of sweet pepper (Capsicum annuиm L.) and on two cultivars of eggplant (Solanum melongena L.). For sweet pepper yield, the $5 \mathrm{~N}-4.8 \mathrm{P}-21.6 \mathrm{~K}$ fertilizer was responsible for the greatest yield for both cultivars. For sweet pepper fresh and dry shoot weight interaction, the 'Orangella' cultivar had greater growth in 5N-4.8P-21.6K and $5 \mathrm{~N}-5.2 \mathrm{P}-21.6 \mathrm{~K}$ fertilizers, whereas there was no difference among cultivars in $7 \mathrm{~N}-3.9 \mathrm{P}-4.1 \mathrm{~K}$. Shape index was not affected by fertilizers or cultivars. For the eggplant yield, there was no main effect nor interaction between fertilizers and cultivars for fruit yield, while the interaction between fertilizers and cultivars was significant for shoot fresh weight production. Shoot fresh weight was greater for 'Angela' than 'Jaylo' in 5N-4.8P-21.6K and 7N-3.9P-4.1K. Furthermore, both eggplant cultivars were affected with yellowing of fruits in all fertilizer treatments after 2 months, which was probably due to the accumulation of nutrients in the closed hydroponic system. Therefore, hydroponic producers could select $5 \mathrm{~N}-4.8 \mathrm{P}-21.6 \mathrm{~K}$ and $5 \mathrm{~N}-5.2 \mathrm{P}-21.6 \mathrm{~K}$ fertilizers for the cultivation of the 'Orangella' cultivar of sweet pepper based on yield. It is important to evaluate more fertilizers and cultivars for eggplant hydroponic cultivation.
\end{abstract}

Keywords: soilless culture; water soluble fertilizers; vegetables; Capsicum annuиm L.; Solanum melongena L.; nutrients; shape index

\section{Introduction}

Problems such as soil salinity, lack of fertile soil, and soil-borne diseases are causes of hindrance for vegetable production in soil. Therefore, to overcome these problems, soilless culture was developed [1]. Involving growing plants without soil, soilless culture is considered a sustainable method for the cultivation of various greenhouse vegetable crops such as tomatoes (Solanum lycopersicum L.), cucumbers (Cucumis sativus L.), peppers (Capsicum L.), lettuce (Lactuca sativa L.), Swiss chard (Beta vulgaris L.), and eggplant (Solanum melongena L.). It is considered good for increasing agriculture sustainability as well as improving environmental health [2]. Soilless culture has various classification systems and methods such as hydroponics, aeroponics, gravel culture, and rockwool culture [3-5]. Dutch bucket system was introduced in the early 1980s by Dutch and Belgian growers and is defined as a container-type hydroponics system filled with substrates to provide support to the plant and nutrient solution supplied by drippers to each container [6].

The most important factor affecting crop yield and quality in hydroponics is nutrient solution [7]. The fertilizer used in hydroponic production should have balanced amounts of essential elements and should not form any precipitates during its use [8]. In most studies, nutrient solutions such as 
Copper's, Hoagland and Arnon's and Yamazaki's solution, which require self-preparation, have been evaluated in the hydroponic production of various crops. The self-preparation of nutrient solution for hydroponic production is effective for large-scale growers, whereas small scale growers face difficulties in managing nutrient concentration [9]. Therefore, commercially prepared, also known as one or two bag approach fertilizers, are gaining popularity. According to Mattson and Peters [9], a single bag fertilizer performed well for the production of peppers, cucumbers, and tomatoes at the University of Arizona Controlled Agriculture Center greenhouse. One of the reasons for the importance of a suitable fertilizer selection in hydroponics is that under field conditions, plants can influence nutrient availability by releasing root exudates or exploring new soil regions by growing their roots, while in hydroponics, it is not possible for plant roots to expand because of the confined area for root growth and the low buffering capacity of roots [10]. Furthermore, the accumulation of nutrients into plant structures may occur if nutrients are supplied in excess, posing health risks when plant products are consumed [11]. In addition, if a food product high in nitrate content is ingested, it is transformed into nitrite and subsequently nitrite, and in combination with amines, may form some carcinogenic compounds [12].

Soilless culture not only offers the possibility of growing crops with considerable savings of water and fertilizers, it is also considered as an easy and rapid method for screening cultivars of different crops for production, drought tolerance, and for physiological disorders [13]. Moreover, cultivar selection for hydroponics is not comparable to cultivar selection for field production. The data derived from field experiments for cultivar selection cannot be directly applied for hydroponic production due to the great difference in growth conditions between the two systems [14]. Some studies have evaluated the performance of sweet pepper cultivars for different objectives. Twelve sweet pepper cultivars were evaluated using a hydroponic system and it was concluded that 'Special' and 'Cupra' for red, 'Boogie', 'Fellini', and 'President' for orange, and 'Fiesta' and 'Derby' for yellow color had greater yields compared to other cultivars [15]. Mineral nutrition has the greatest impact on some physical and quality characteristics of sweet pepper, which include soluble solids, $\mathrm{pH}$, fruit shape index, firmness, and pulp thickness [9]. It has also been also suggested that fruit weight and fruit shape index are two important characteristics of sweet peppers determining consumer preference and acceptability [16].

Various cultivars are available in the market for each crop, but for hydroponic cultivation, it is also necessary that the cultivar have a high economic value due to high input costs $[5,8]$. The yellow and orange colored cultivars of sweet peppers have a higher economic value than green colored cultivars. Therefore, 'Orangella' and 'Bentley' are orange and yellow colored cultivars of sweet pepper, respectively. Among the eggplant cultivars, 'Angela' and 'Jaylo' have been reported to have higher economic values due to their greater fruit size and white stripped fruits, respectively. Due to their high economic value, these cultivars has been tested with different objectives in hydroponic production. 'Bentley' has been tested for susceptibility to Fusarium spp. and other water-borne diseases in hydroponic cultivation [17]. Nevertheless, scientific literature evaluating these sweet pepper and eggplant cultivars using different commercially available hydroponic fertilizers is still lacking. Therefore, the objectives of our study were to evaluate the effect of three different commercial hydroponic fertilizers on growth, fruit production, and fruit quality (fruit shape index) parameters of different cultivars of sweet pepper and eggplant in the Dutch bucket system.

\section{Materials and Methods}

\subsection{Plant Materials and Growth Conditions}

Seeds of sweet peppers 'Bentley' and 'Orangella' and eggplants 'Angela' and 'Jaylo' were obtained from Johnny's Selected Seeds (Winslow, ME, USA) and sown on 12 February 2016. The seeds were sown in $1.5 \mathrm{~cm}^{3}$ rockwool starter cubes with a sheet of 98 cubes (Grodan, Milton, ON, Canada) and transplanted into a Dutch bucket system on 20 March 2016 at the Department of Horticulture and Landscape Architecture Research Greenhouses in Stillwater, OK, USA. The average daily temperature, 
measured using a data logger (T \& D Corporation, Nagano, Japan), was $27.2^{\circ} \mathrm{C}$. Light was measured using the same sensor and the daily light integral (DLI) was calculated from this data by multiplying 7992.48 lux by 0.0185 (standard conversion factor for sunlight to convert lux to PPFD), then multiplying $172.9 \mu \mathrm{mol} \mathrm{m}{ }^{-2} \mathrm{~s}^{-1}$ by 0.0864 (standard conversion based on the total number of seconds in a day divided by 1 million) to obtain a DLI average of $12.8 \mathrm{~mol} \mathrm{~m}^{-2} \mathrm{~d}^{-1}$ for sweet pepper production [8]. For eggplant production, the average lux for the growth period was 8701.23 lux, therefore, DLI was equal to $13.90 \mathrm{~mol} \mathrm{~m}^{-2} \mathrm{~d}^{-1}$. No nutrition was provided during nursery production. Seeds for the second replication were sown on 15 February 2017 and transplanted into the system on 23 March 2017. A single plant was transplanted into each bucket. The Dutch buckets were placed $50 \mathrm{~cm}$ apart and the rows were $100 \mathrm{~cm}$ apart and arranged on the opposite side of the irrigation and drainage pipes. Water was provided to each plant by a drip emitter, which supplied $3.75 \mathrm{~L}$ of water per $\mathrm{h}$. Buckets were filled with expanded clay pebbles (Mother Earth Hydroton, National Garden Wholesale Sunlight Supply, Vancouver, WA, USA). The water that drained away was recirculated from a $150 \mathrm{~L}$ capacity storage tank using an electric pump.

\subsection{Fertilizers}

Both crops were fertilized by 5N-4.8P-21.6K (Jack's, J.R. Peters, Allentown, PA, USA), 5N-5.2P-21.6K (Peters, J.R. Peters, Allentown, PA, USA), and 7N-3.9P-4.1K (Dyna Gro, Richmond, CA, USA). The fertilizers used in this experiment had different elemental compositions (Table 1). Fertilizers $5 \mathrm{~N}-4.8 \mathrm{P}-21.6 \mathrm{~K}$ and $5 \mathrm{~N}-5.2 \mathrm{P}-21.6 \mathrm{~K}$ did not contain calcium $(\mathrm{Ca})$ in their formulation, therefore, it was recommended by the manufacturer to add calcium nitrate $\left(\mathrm{CaNO}_{3}\right)($ Haifa North America, Inc., Altamonte Spring, FL, USA) to supply Ca and a fraction of nitrogen (N). Fertilizer 7N-3.9P-4.1K contained all the recommended dosages of nutrients in one formulation. Tap water with an electrical conductivity (EC) of $0.5 \mathrm{dS} \mathrm{m}^{-1}$ and a $\mathrm{pH}$ of 7.8 was used to prepare the nutrient solution.

Table 1. Nutrient concentrations (in ppm) of hydroponic fertilizers when $3.69 \mathrm{~kg}$ were dissolved in 3785.4 L of water (as suggested by manufacturer).

\begin{tabular}{cccc}
\hline Nutrients & $\begin{array}{c}\text { Concentrations for } \\
\text { 5N-4.8P-21.6K }\end{array}$ & $\begin{array}{c}\text { Concentrations for } \\
\text { 5N-5.2P-21.6K }\end{array}$ & $\begin{array}{c}\text { Concentrations for } \\
\text { 7N-3.9P-4.1K }\end{array}$ \\
\hline Nitrogen & 150.00 & 150.00 & 188.00 \\
Phosphorus & 39.00 & 48.00 & 41.00 \\
Potassium & 216.00 & 216.00 & 134.00 \\
Calcium & 139.00 & 139.00 & 53.00 \\
Magnesium & 47.00 & 31.00 & 13.44 \\
Iron & 2.30 & 3.00 & 2.68 \\
Manganese & 0.38 & 0.05 & 1.34 \\
Zinc & 0.11 & 0.15 & 1.34 \\
Boron & 0.38 & 0.50 & 0.53 \\
Copper & 0.13 & 0.15 & 1.34 \\
Molybednum & 0.07 & 0.10 & 0.02 \\
\hline
\end{tabular}

\subsection{EC, $p H$, and Data Collection}

Sweet pepper fruits were harvested when $80 \%$ color (yellow or orange) development occurred and eggplants were harvested when they reached full size (i.e., weighing 250-400 g). Harvesting was carried out once or twice a week depending on number and maturity stage of fruits. The EC of all the nutrient solutions was maintained at $2.5-3.5 \mathrm{dS} \mathrm{m}^{-1}$. If EC was higher than the recommended limit, then water was added and if $\mathrm{EC}$ was lower, then some fertilizer was added. The $\mathrm{pH}$ was maintained at 5.5-6.5 for eggplants and 5.5-6 for peppers. The commercially available product $\mathrm{pH}$ down (General Hydroponics, Santa Rosa, CA, USA) were used to adjust $\mathrm{pH}$. This product was reported to be best among different organic and inorganic products used for $\mathrm{pH}$ maintenance in hydroponics [18]. The $\mathrm{pH}$ and EC of the solution was checked every alternate day. 
At each harvest, data were collected on fruit weight and fruit shape index (for sweet pepper). Shape index was defined by the equatorial to longitudinal length ratio and calculated by dividing the maximum height $(\mathrm{H})$ of fruit to the maximum width $(\mathrm{W})$ of fruit $(\mathrm{H} / \mathrm{W})$ [19]. The height and width of each fruit were measured from randomly selected fruit. Nutrient analysis was conducted for the leaves of sweet peppers and eggplants. The nutrient analysis data for sweet pepper are not presented because there were no nutritional disorders in sweet pepper and nutrient concentration were within recommended limits. At the end of the trial, data were collected on fresh shoot weight, dry shoot, and root weight (shoots and roots dried for 2 days at $56^{\circ} \mathrm{C}$ ). Nutrient analysis of leaf samples was analyzed by the Soil, Water and Forage Analytical Laboratory at Oklahoma State University, using a nutrient analyzer (TruSpec Elemental Analyzer; LECO Corp, St. Joseph, MI, USA).

\subsection{Experimental Setup and Data Analyses}

The experimental design was a split plot design with two replications over time. The factors were fertilizer (main plots, three levels) and cultivars (sub plots, two levels for each crop). The experimental unit for the fertilizer was 18 plants, while the experimental unit for the cultivar was nine plants of each crop. Therefore, for each fertilizer treatment, there were nine replicas of each cultivar. Tests of significance were performed at the $0.05,0.001$, and 0.0001 levels. Least significance difference (LSD) method was used for comparing differences between treatment means. Data analysis was generated using SAS/STAT software (version 9.4) [20].

\section{Results}

\subsection{Sweet Pepper}

Interactions between fertilizer and sweet pepper cultivars occurred for shoot fresh and dry weight, and average fruit weight (Table 2). Shoot fresh weight and dry weight were significantly greater for 'Orangella' as compared to 'Bentley' when fertilized with 5N-4.8P-21.6K and 5N-5.2P-21.6K (Figures 1 and 2). There was no significant difference between shoot fresh and dry weight between sweet pepper cultivars when fertilized with 7N-3.9P-4.1K (Figures 1 and 2). Average fruit weight was significantly greater for 'Orangella' as compared to 'Bentley' when fertilized with 5N-4.8P-21.6K, whereas there was no significant difference between two cultivars when fertilized with 5N-5.2P-21.6K and 7N-3.9P-4.1K (Figure 3). Average fruit weight ranged from 122-172 g.

Table 2. Interaction and main effect for sweet pepper ('Bentley' and 'Orangella'), eggplant ('Angela' and 'Jaylo'), and hydroponic fertilizers (5N-4.8P-21.6K, 5N-5.2P-21.6K, and 7N-3.9P-4.1K).

\begin{tabular}{|c|c|c|c|c|}
\hline & Crops & Cultivar & Fertilizer & Cultivar * Fertilizer \\
\hline \multirow{2}{*}{ Yield } & Sweet pepper & $\mathrm{NS}^{\mathrm{z}}$ & $*$ & NS \\
\hline & Eggplant & NS & NS & NS \\
\hline \multirow{2}{*}{ Shoot fresh weight } & Sweet pepper & $* * *$ & NS & $* *$ \\
\hline & Eggplant & $* *$ & $* * *$ & * \\
\hline \multirow{2}{*}{ Root weight } & Sweet pepper & NS & $* * *$ & NS \\
\hline & Eggplant & NS & NS & NS \\
\hline \multirow{2}{*}{ Shoot dry weight } & Sweet pepper & $* * *$ & NS & $*$ \\
\hline & Eggplant & $* * *$ & $* * *$ & NS \\
\hline Shape index & Sweet pepper & NS & NS & NS \\
\hline Average fruit weight & Sweet pepper & NS & NS & * \\
\hline
\end{tabular}

For fruit yield and root weight, there was a significant fertilizer effect, while there was no fertilizer or cultivar effect for shape index (Table 2). The fruit yield of sweet pepper was significantly greater in $5 \mathrm{~N}-4.8 \mathrm{P}-21.6 \mathrm{~K}$ and $5 \mathrm{~N}-5.2 \mathrm{P}-21.6 \mathrm{~K}$ as compared to $7 \mathrm{~N}-3.9 \mathrm{P}-4.1 \mathrm{~K}$ (Table 3). The root weight of sweet 
pepper was significantly greater in $5 \mathrm{~N}-4.8 \mathrm{P}-21.6 \mathrm{~K}$ as compared to $5 \mathrm{~N}-5.2 \mathrm{P}-21.6 \mathrm{~K}$ and $7 \mathrm{~N}-3.9 \mathrm{P}-4.1 \mathrm{~K}$ (Table 3).

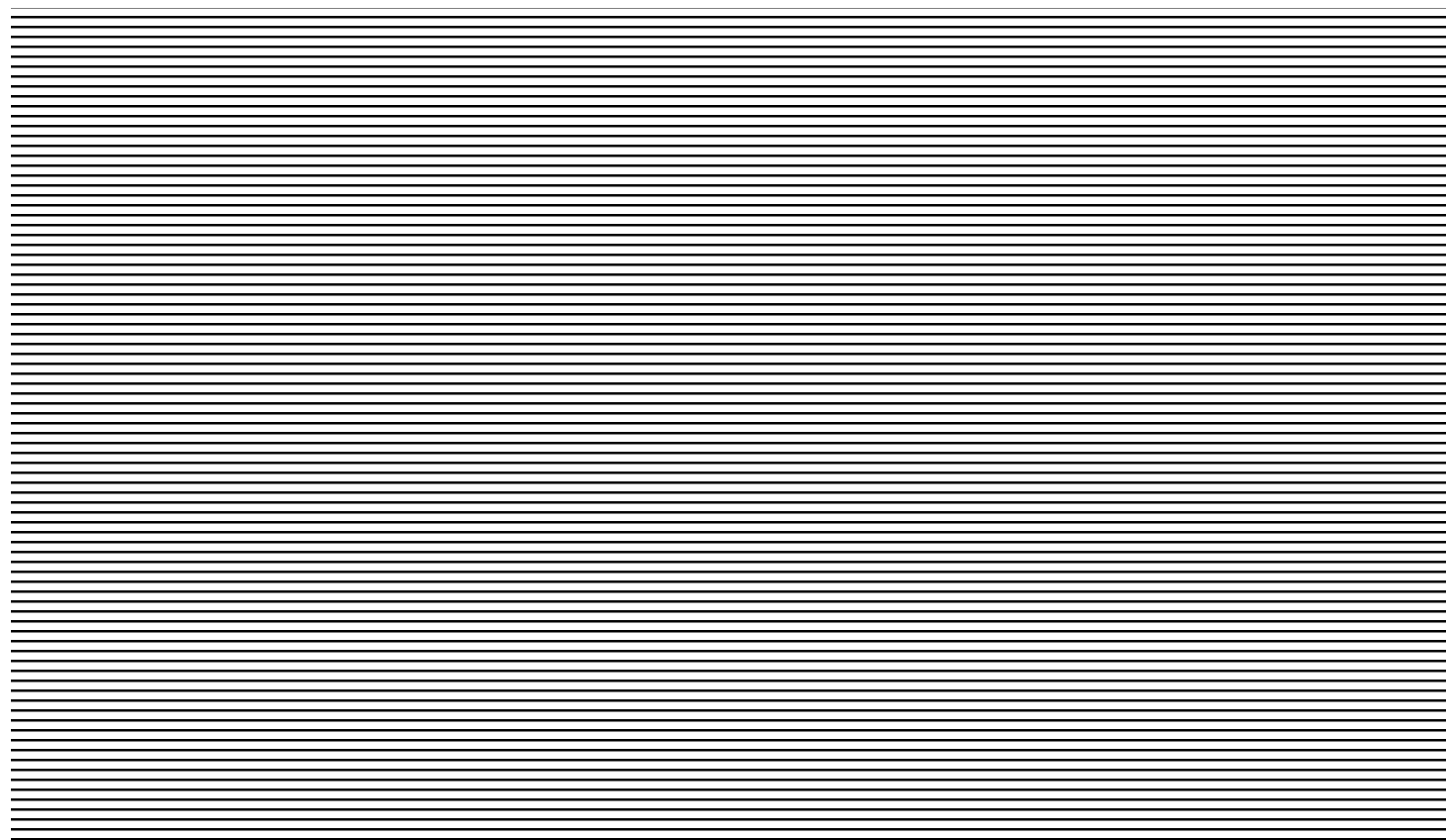

Figure 1. Interaction between sweet pepper cultivars ('Bentley' and 'Orangella') and hydroponic fertilizers (5N-4.8P-21.6K, 5N-5.2P-21.6K, and 7N-3.9P-4.1K) for shoot fresh weight (g) per plant $(\mathrm{n}=9)$. Data are presented as means \pm SEM. Means with same lowercase letter are not significantly different by LSD $(p \leq 0.05)$ between cultivars within fertilizers. Means with same uppercase letter are not significantly different by LSD $(p \leq 0.05)$ among fertilizers within each cultivar.

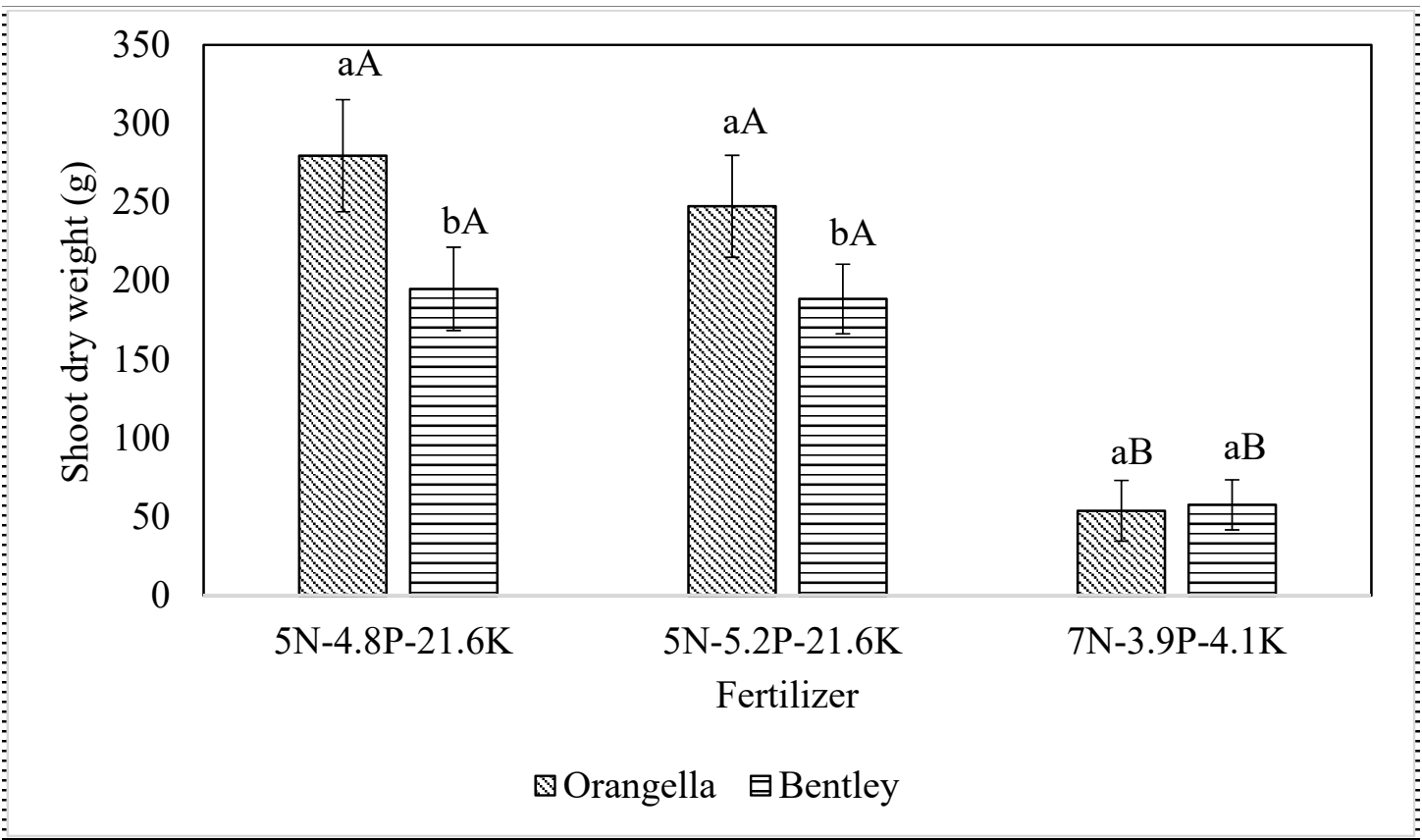

Figure 2. Interaction between sweet pepper cultivars ('Bentley' and 'Orangella') and hydroponic fertilizers $(5 \mathrm{~N}-4.8 \mathrm{P}-21.6 \mathrm{~K}, 5 \mathrm{~N}-5.2 \mathrm{P}-21.6 \mathrm{~K}$, and 7N-3.9P-4.1K) for shoot dry weight $(\mathrm{g})$ per plant $(\mathrm{n}=9)$. Data are presented as means $\pm \mathrm{SEM}$. Means with same lowercase letter are not significantly different by LSD $(p \leq 0.05)$ between cultivars within fertilizers. Means with same uppercase letter are not significantly different by LSD $(p \leq 0.05)$ among fertilizers within each cultivar. 


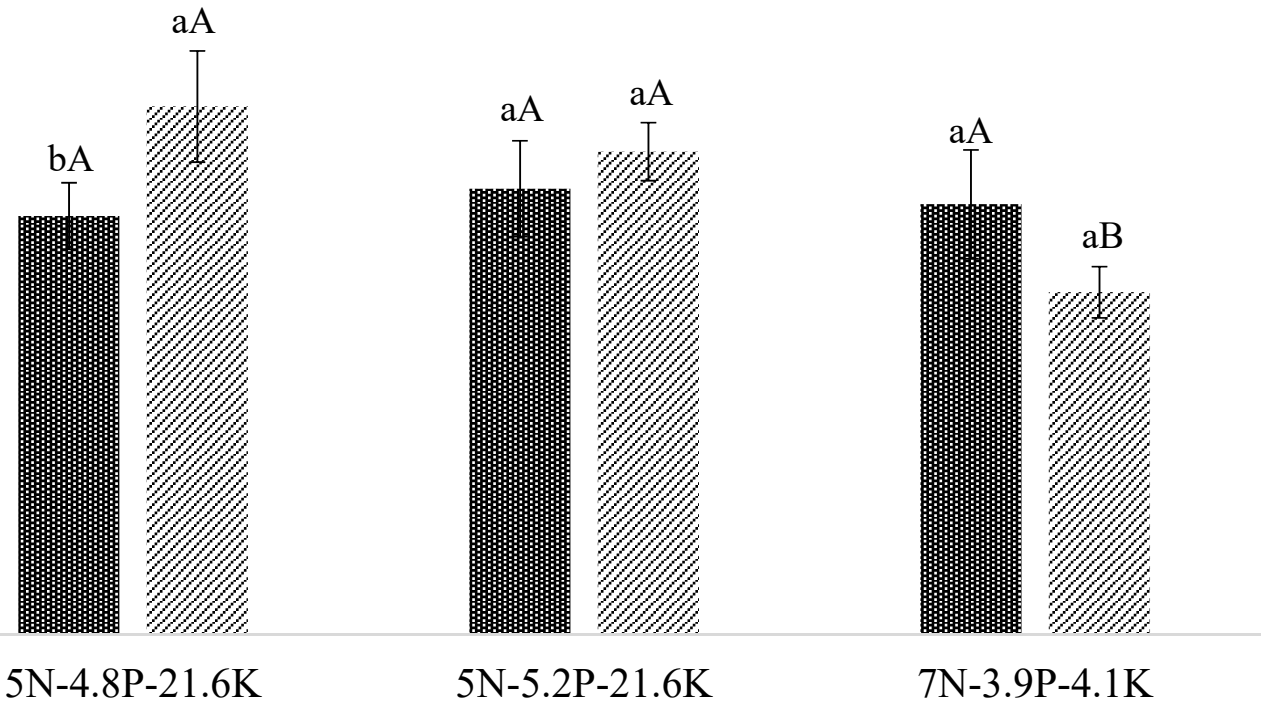

賉Orangella $\mathbb{Z}$ Bentley

Figure 3. Interaction between sweet pepper cultivars ('Bentley' and 'Orangella') and hydroponic fertilizers $(5 \mathrm{~N}-4.8 \mathrm{P}-21.6 \mathrm{~K}, 5 \mathrm{~N}-5.2 \mathrm{P}-21.6 \mathrm{~K}$, and $7 \mathrm{~N}-3.9 \mathrm{P}-4.1 \mathrm{~K})$ for average fruit weight (g) per plant $(\mathrm{n}=9)$. Data are presented as means \pm SEM. Means with same lowercase letter are not significantly different by LSD $(p \leq 0.05)$ between cultivars within fertilizers. Means with same uppercase letter are not significantly different by LSD $(p \leq 0.05)$ among fertilizers within each cultivar.

Table 3. Main effect of hydroponic fertilizers (5N-4.8P-21.6K, 5N-5.2P-21.6K, 7N-3.9P-4.1K) pooled across cultivars for per plant sweet pepper fruit yield and root weight. $(n=18)$.

\begin{tabular}{ccc}
\hline Fertilizer & Yield $(g)$ & Root Weight $(g)$ \\
\hline $5 N-4.8 P-21.6 \mathrm{~K}$ & $3697.76 \pm 352.42 \mathrm{a}^{\mathrm{z}}$ & $104.47 \pm 12.80 \mathrm{a}$ \\
$5 \mathrm{~N}-5.2 \mathrm{P}-21.6 \mathrm{~K}$ & $3080.97 \pm 489.84 \mathrm{a}$ & $86.60 \pm 4.56 \mathrm{~b}$ \\
$7 \mathrm{~N}-3.9 \mathrm{P}-4.1 \mathrm{~K}$ & $1378.47 \pm 375.41 \mathrm{~b}$ & $39.11 \pm 8.96 \mathrm{c}$ \\
\hline
\end{tabular}

${ }^{\mathrm{z}}$ Means within a column followed by same lowercase letter are not significantly different by LSD $(p \leq 0.05)$. Data are presented as means \pm SEM.

\subsection{Eggplant}

Interactions between fertilizer and eggplant cultivars occurred for shoot fresh weight. The shoot fresh weight was significantly greater for 'Angela' as compared to 'Jaylo' when fertilized with $5 \mathrm{~N}-4.8 \mathrm{P}-21.6 \mathrm{~K}$ and $7 \mathrm{~N}-3.9 \mathrm{P}-4.1 \mathrm{~K}$. There was no significant difference between the shoot fresh weights of eggplant cultivars when fertilized with 5N-5.2P-21.6K (Figure 4). 


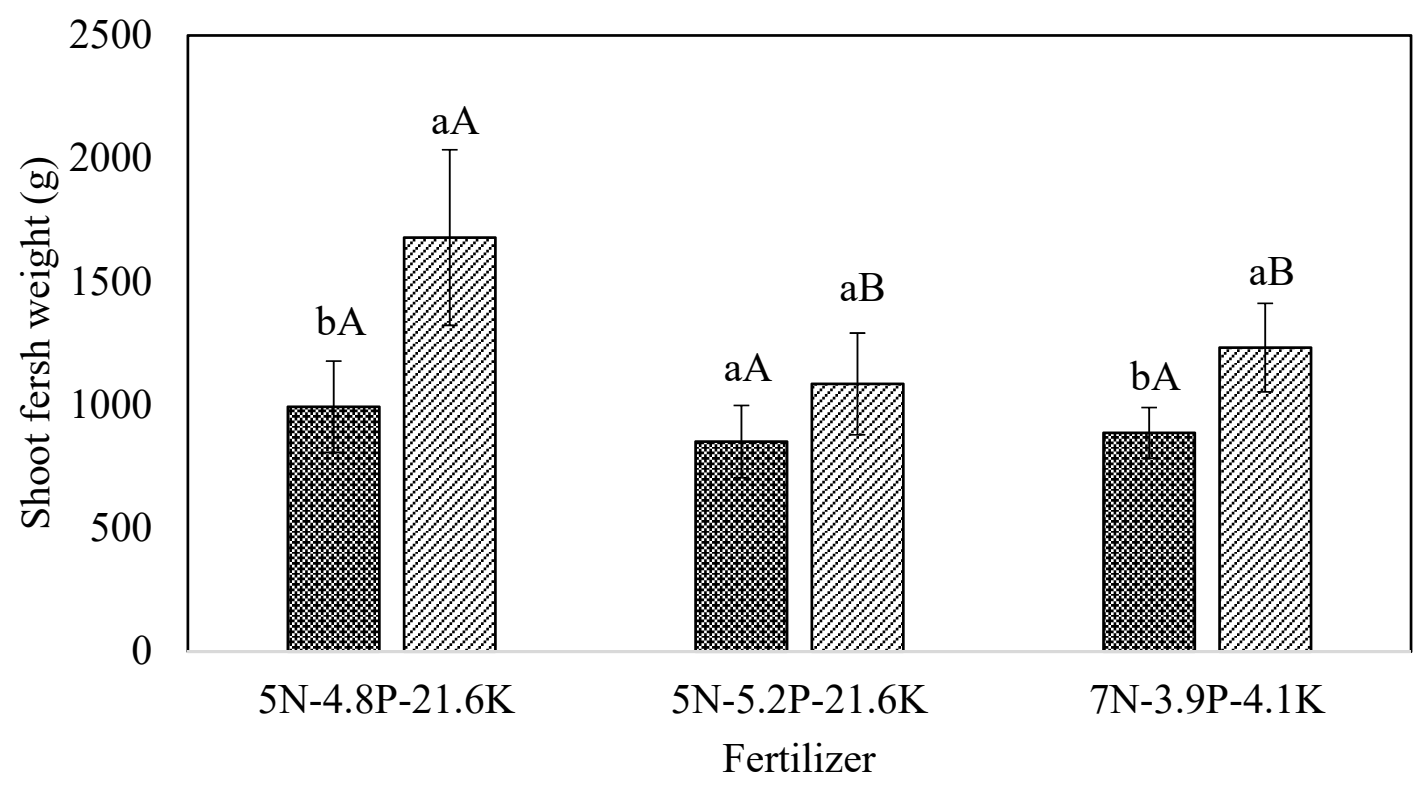

* Jaylo $\square$ Angela

Figure 4. Interaction between eggplant cultivars ('Angela' and 'Jaylo') and hydroponic fertilizers (5N-4.8P-21.6K, 5N-5.2P-21.6K, and 7N-3.9P-4.1K) for shoot fresh weight $(\mathrm{g})(\mathrm{n}=9)$. Data are presented as means \pm SEM. Means with the same lowercase letter are not significantly different by LSD $(p \leq 0.05)$ between cultivars within fertilizers. Means with same uppercase letter are not significantly different by LSD $(p \leq 0.05)$ among fertilizers within each cultivar.

A fertilizer effect was found on the shoot dry weight, while a cultivar main effect was only found for the shoot dry weight of eggplant (Table 2). There was no significant difference for yield and root weight among different fertilizer treatments (Table 2). The shoot dry weight of eggplant was significantly greater in $5 \mathrm{~N}-4.8 \mathrm{P}-21.6 \mathrm{~K}$ as compared to $5 \mathrm{~N}-5.2 \mathrm{P}-21.6 \mathrm{~K}$ and $7 \mathrm{~N}-3.9 \mathrm{P}-4.1 \mathrm{~K}$ when pooled across cultivars (Table 4). The shoot dry weight of 'Angela' was significantly greater than 'Jaylo' when pooled across fertilizers (Table 4).

Table 4. Main effect of hydroponic fertilizers (5N-4.8P-21.6K, 5N-5.2P-21.6K, 7N-3.9P-4.1K) pooled across cultivars $(\mathrm{n}=18)$ and eggplant cultivars ('Angela' and 'Jaylo') pooled across fertilizers for shoot dry weight. $(\mathrm{n}=9)$.

\begin{tabular}{cccc}
\hline Fertilizer & Shoot Dry Weight $(g)$ & Cultivar & Shoot Dry Weight(g) \\
\hline $5 \mathrm{~N}-4.8 \mathrm{P}-21.6 \mathrm{~K}$ & $204.07 \pm 5.50 \mathrm{a}^{\mathrm{z}}$ & Jaylo & $184.30 \pm 10.52 \mathrm{~b}$ \\
$5 \mathrm{~N}-5.2 \mathrm{P}-21.6 \mathrm{~K}$ & $191.26 \pm 3.07 \mathrm{~b}$ & Angela & $248.20 \pm 8.96 \mathrm{a}$ \\
$7 \mathrm{~N}-3.9 \mathrm{P}-4.1 \mathrm{~K}$ & $193.42 \pm 4.52 \mathrm{~b}$ & & \\
\hline
\end{tabular}

\footnotetext{
${ }^{\mathrm{z}}$ Means within a column followed by same lowercase letter are not significantly different by LSD $(p \leq 0.05)$. Data are presented as means \pm SEM.
}

Eggplant fruits developed an abnormal color after 2 months of production in both years. The fruits of the 'Jaylo' cultivar turned brownish-purple in color, while the 'Angela' cultivar fruits developed a yellow color. Foliar analysis found that the concentration of all nutrients was above the recommended upper limit except $\mathrm{N}$ (Table 5). A pairwise comparison was performed between the recommended foliar nutrient concentration by Flores et al. [21] and foliar nutrient concentration of plants grown in different fertilizers was observed. 
Table 5. Average foliar nutrient concentration for eggplant in comparison to recommended nutrient level by Flores [21] $(\mathrm{n}=18)$.

\begin{tabular}{ccccc}
\hline Nutrients & Recommended & 5N-4.8P-21.6K & 5N-5.2P-21.6K & 7N-3.9P-4.1K \\
\hline Nitrogen $(\%)$ & $4.20 \mathrm{a}^{\mathrm{z}}$ & $3.64 \pm 0.64 \mathrm{a}$ & $3.55 \pm 0.70 \mathrm{a}$ & $3.62 \pm 0.60 \mathrm{a}$ \\
Phosphorus $* * \mathrm{y}(\%)$ & $0.30 \mathrm{~b}$ & $0.39 \pm 0.04 \mathrm{a}$ & $0.42 \pm 0.10 \mathrm{a}$ & $0.38 \pm 0.05 \mathrm{a}$ \\
Potassium $* *(\%)$ & $3.50 \mathrm{~b}$ & $3.96 \pm 0.25 \mathrm{a}$ & $3.95 \pm 0.29 \mathrm{a}$ & $3.72 \pm 0.26 \mathrm{~b}$ \\
Calcium ${ }^{* * *}(\%)$ & $0.80 \mathrm{~b}$ & $3.82 \pm 0.90 \mathrm{a}$ & $4.02 \pm 0.95 \mathrm{a}$ & $3.63 \pm 1.05 \mathrm{a}$ \\
Magnesium $* *(\%)$ & $0.25 \mathrm{~b}$ & $0.96 \pm 0.42 \mathrm{a}$ & $1.02 \pm 0.56 \mathrm{a}$ & $0.92 \pm 0.47 \mathrm{a}$ \\
Manganese ${ }^{* * *}(\mathrm{ppm})$ & $50.00 \mathrm{c}$ & $130.25 \pm 26.89 \mathrm{a}$ & $156.30 \pm 45.85 \mathrm{a}$ & $144.80 \pm 62.53 \mathrm{a}$ \\
Iron $^{* * *}(\mathrm{ppm})$ & $50.00 \mathrm{~b}$ & $155.02 \pm 39.01 \mathrm{a}$ & $144.05 \pm 52.65 \mathrm{a}$ & $158.10 \pm 55.12 \mathrm{a}$ \\
Boron $^{* * *}(\mathrm{ppm})$ & $20.00 \mathrm{~b}$ & $80.50 \pm 37.02 \mathrm{a}$ & $88.89 \pm 51.46 \mathrm{a}$ & $96.30 \pm 24.05 \mathrm{a}$ \\
Zinc $^{* * *}(\mathrm{ppm})$ & $20.00 \mathrm{~b}$ & $76.60 \pm 16.92 \mathrm{a}$ & $72.08 \pm 18.56 \mathrm{a}$ & $75.42 \pm 25.09 \mathrm{a}$ \\
\hline
\end{tabular}
${ }^{\mathrm{z}}$ Means within a row followed by same letter are not significantly different by paired $\mathrm{t}$ test $(p \leq 0.05) . \mathrm{y}, *, * * * * *$
indicates non-significant or significant at $p \leq 0.05, p \leq 0.001$, or $p \leq 0.0001$, respectively. Data are presented as means \pm SEM.

\section{Discussion}

Fruit weight and fruit shape index are two important characteristics of sweet peppers, determining the fruit quality [22]. For sweet pepper, fruits weighing less than $100 \mathrm{~g}$ are considered to be unmarketable [22]; in the current trial, the sweet pepper average fruit weight ranged from 122-172 $\mathrm{g}$ (Figure 3). Rubio et al. [22] also looked for the response of Ca and $\mathrm{K}$ on the yield and fruit quality of sweet pepper and found that adequate management of $\mathrm{Ca}$ and $\mathrm{K}$ fertilization could help improve yield and fruit quality (fruit shape index) of sweet pepper in hydroponics. The findings from the current experiment for sweet pepper fruit yield support the results from Rubio et al. [22], as high yielding fertilizers $5 \mathrm{~N}-4.8 \mathrm{P}-21.6 \mathrm{~K}$ and $5 \mathrm{~N}-5.2 \mathrm{P}-21.6 \mathrm{~K}$ were high in $\mathrm{Ca}$ and $\mathrm{K}$ as compared to $7 \mathrm{~N}-3.9 \mathrm{P}-4.1 \mathrm{~K}$, whereas there was no effect on fruit quality (fruit shape index). Fertilizer $5 \mathrm{~N}-4.8 \mathrm{P}-21.6 \mathrm{~K}$ has been recommended for hydroponic production of tomatoes, cucumbers, and peppers and was found to be similar in nutrient content with the hydroponic recipe prepared by the University of Arizona, which provided remarkable results [9].

Another study evaluated the effect of nutrition and irrigation on sweet pepper production in hydroponics and concluded that in a closed system, the fertilization of nitrogen (N) 240, phosphorus (P) 60, (K) 300, magnesium (Mg) 50, ferrous (Fe) 6, manganese (Mn) 3, boron (B) 1.6, zinc ( $\mathrm{Zn}$ ) 2, (Ca) 90, copper $(\mathrm{Cu}) 0.8$ and molybdenum $(\mathrm{Mo}) 0.12\left(\mathrm{mg} \mathrm{L}^{-1}\right)$ was appropriate for sweet pepper production [23]. Therefore, there is a possibility of a further increase in fruit yield for current sweet pepper cultivars because all the nutrient levels of the current fertilizers were lower than the levels recommended by Gul et al. [23] (Table 1). Adding potassium peroxide at a rate of $1 \mathrm{~g} \mathrm{~L}^{-1}$ has also been reported to result in a $20 \%$ increase in sweet pepper yield in hydroponics [24].

For hydroponic eggplant production, we did not find any recommendations of specific fertilizers in the literature other than self-preparation of Hoagland's solution [25]. However, since the manufacturer recommended that the fertilizers tested in the current trial were suitable for fruiting vegetable crops, they were tested for eggplants. Both the form and quantity of N play important roles in hydroponic as well as field vegetable production. The nitrate form of $\mathrm{N}$ should dominate in the nutrient solution, while the ammoniacal form should be lower [25]. In the current study, fertilizers 5N-4.8P-21.6K and $5 \mathrm{~N}-5.2 \mathrm{P}-21.6 \mathrm{~K}$ had a total $\mathrm{N}$ in nitrate form while $7 \mathrm{~N}-3.9 \mathrm{P}-4.1 \mathrm{~K}$ had $2.6 \%$ as ammoniacal form and $4.4 \%$ as nitrate form. In terms of the quantity of $\mathrm{N}$, the recommendation of total $\mathrm{N}$ for hydroponic production of eggplants was 120-170 ppm, which was satisfied by the fertilizers used in our study [26]. There was limited literature providing information regarding micronutrient requirements of eggplant in soilless culture. It has been reported that eggplants need $15,10,5,0.75$ and $0.5 \mu \mathrm{M}$ of $\mathrm{Fe}, \mathrm{Mn}, \mathrm{Zn}, \mathrm{Cu}$, and Mo, respectively [26].

The yellowing of eggplant leaves and fruits was initially suspected to be caused by a deficiency of some nutrients. Eggplant is susceptible to boron deficiency and young fully developed leaves turn 
yellow at the distal end [27]. However, foliar analysis of eggplant revealed that the concentration of all the nutrients was above the recommended limit except $\mathrm{N}$ (Table 5). Therefore, the yellowing in plants was more likely due to the toxicity of nutrients. A possible reason explaining this nutrient toxicity in hydroponic eggplant production is the use of expanded clay balls as a stand-alone substrate. Some substrates may have a higher cation-exchange capacity, thereby leading to the localization of some nutrients in root zones and to the toxicity of nutrients. Pine bark has been suggested to be the best stand-alone substrate for fruit vegetable production [28]. Another reason explaining nutrient toxicity could be the higher accumulation of macro and micronutrients in closed hydroponic systems reported in some studies [29]. Therefore, the selection of an adequate stand-alone substrate is important for hydroponic vegetable production to avoid yield loss due to nutrient toxicity [30]. Moreover, there is need for an appropriate method to monitor nutrient concentration in solution during growing cycles.

Many studies have reported different EC ranges for the hydroponic cultivation of eggplants. The response of eggplant to salinity in a recirculating hydroponics system was studied by Savvas et al. [26], who found that high salinity significantly affected osmotic potential due to reduced water uptake leading to less water being directed towards fruit development and they recommended an EC of $1.5 \mathrm{dS} \mathrm{m}^{-1}$. Moazed et al. [31] and Mahjoor et al. [32] recommend an EC of $2.5 \mathrm{dS} \mathrm{m}^{-1}$. According to the foliar nutrient concentrations, by maintaining the EC in the recommended range $\left(2.5-3.5 \mathrm{dS} \mathrm{m}^{-1}\right)$, plants were not able to maintain nutrient concentration in required limits as the concentration of all the nutrients except $\mathrm{N}$ was higher than the recommended range. Therefore, some researchers have reported that the EC is not a good indicator for estimating the nutrient concentration of solution, as EC indicates total dissolved ion concentrations only and cannot be used directly to determine individual ion concentrations. Thus, controlling nutrients based on EC in hydroponics may lead to excess or deficiency of some nutrients [33]. Periodic tissue sampling is reported to be the best way to evaluate if the nutrients provided are adequate for the growth stage and growing conditions [9]. Furthermore, some other non-destructive precision agriculture tools, such as mobile phone plant nitrogen applications, can be used to monitor nutrient concentrations in greenhouse production [34].

\section{Conclusions}

From the results of the present experiment, $5 \mathrm{~N}-4.8 \mathrm{P}-21.6 \mathrm{~K}$ and $5 \mathrm{~N}-5.2 \mathrm{P}-21.6 \mathrm{~K}$ can be recommended for sweet pepper production in hydroponics because fruit yield was not significantly different between these fertilizers, whereas it was significantly greater than with $7 \mathrm{~N}-3.9 \mathrm{P}-4.1 \mathrm{~K}$. For cultivar evaluation, 'Orangella' produced significantly greater shoot fresh and dry weight in $5 \mathrm{~N}-4.8 \mathrm{P}-21.6 \mathrm{~K}$ and $5 \mathrm{~N}-5.2 \mathrm{P}-21.6 \mathrm{~K}$. Nevertheless, vegetable producers are more interested in fruit yield and quality. The average fruit weight of 'Orangella' was significantly lower than 'Bentley' when grown in $5 \mathrm{~N}-4.8 \mathrm{P}-21.6 \mathrm{~K}$. Moreover, some other factors needed to be evaluated to recommend these cultivar for hydroponic production because some studies reported 'Bentley' to be susceptible to Fusarium and to water borne disease [17]. Two months data for eggplants showed that there was no effect of cultivar or fertilizer on eggplant yield, while the main effects of cultivar and fertilizer were observed for shoot dry weight, with 'Angela' producing significantly greater results than 'Jaylo' and 5N-4.8P-21.6K producing significantly greater results among the three fertilizers. An interaction among fertilizers and eggplant cultivars was observed for eggplant shoot fresh weight, with 'Angela' producing significantly greater weight in $5 \mathrm{~N}-4.8 \mathrm{P}-21.6 \mathrm{~K}$ and $7 \mathrm{~N}-3.9 \mathrm{P}-4.1 \mathrm{~K}$. Based on the results of the current study, it is not possible to recommend either fertilizer or cultivar for the hydroponic production of eggplant, as after 2 months, almost all the fruits were non-marketable due to yellowing. Therefore, future studies are needed to investigate the physiology behind the yellowing of eggplant fruits, and to identify a better indicator of nutrient concentration than EC. Different recycling rates of nutrient solutions and alternatives for stand-alone substrates for eggplant hydroponic production should be evaluated in future studies because this will also affect nutrient accumulation into plant parts. 
Author Contributions: Conceptualization, B.L.D.; H.S.; methodology, H.S.; formal analysis, M.P.; investigation, H.S.; writing—original draft preparation, H.S.; writing—review and editing, B.L.D.; H.S.; and L.B.; supervision, B.L.D.

Funding: This research was funded by ODAFF Specialty Block grant \#G00000475.

Conflicts of Interest: We declare no conflict of interest.

\section{References}

1. Savvas, D.; Gruda, N. Application of soilless culture technologies in the modern greenhouse industry-A review. Eur. J. Hortic. Sci. 2018, 83, 280-293. [CrossRef]

2. Gruda, N.; Savvas, D.; Colla, G.; Rouphael, Y. Impacts of genetic material and current technologies on product quality of selected greenhouse vegetables-A review. Eur. J. Hortic. Sci. 2018, 83, 319-328. [CrossRef]

3. Van, E.; Gieling, T.; Lieth, H. Technical Equipment in Soilless Production Systems. In Soilless Culture Theory and Practice; Elsevier: London, UK, 2008; pp. 147-207.

4. Atzori, G.; Mancuso, S.; Masi, E. Seawater potential use in soilless culture: A review. Sci. Hortic. 2019, 249, 199-207. [CrossRef]

5. Lennard, W.; Leonard, B. A comparison of three different hydroponic sub-systems (gravel bed, floating and nutrient film technique) in an aquaponic test system. Aquac. Int. 2006, 14, 539-550. [CrossRef]

6. Roberto, K. How to Hydroponics; The Future Garden Press: Farmingdale, NY, USA, 2003; p. 22.

7. Savvas, D.; Gizas, G. Response of hydroponically grown gerbera to nutrient solution recycling and different nutrient cation ratios. Sci. Hortic. 2002, 96, 267-280. [CrossRef]

8. Singh, H.; Dunn, B.; Payton, M.; Brandenberger, L. Fertilizer and cultivar selection of lettuce, basil, and swiss chard for hydroponic production. HortTechnology 2019, 29, 50-56. [CrossRef]

9. Mattson, N.S.; Peters, C. A Recipe for Hydroponic Success, Inside Grower; Ball Publishing: Chicago, IL, USA, 2014; pp. 16-19.

10. Savvas, D.; Ntatsi, G.; Rodopoulou, M.; Goumenaki, F. Nutrient uptake concentrations in a cucumber crop grown in a closed hydroponic system under Mediterranean climatic conditions as influenced by irrigation schedule. Acta Hortic. 2014, 1034, 545-552. [CrossRef]

11. Cavarianni, R.L.; Cecílio Filho, A.B.; Cazetta, J.O.; May, A.; Corradi, M. Nutrient contents and production of rocket as affected by nitrogen concentrations in the nutritive solution. Sci. Agric. 2008, 65, 652-658. [CrossRef]

12. Elwan, M.; El-Hamed, K. Influence of nitrogen form, growing season and sulfur fertilization on yield and the content of nitrate and vitamin C of broccoli. Sci. Hortic. 2011, 127, 181-187. [CrossRef]

13. Ogbonnaya, C.; Sarr, B.; Brou, C.; Diouf, O.; Diop, N.; Roy-Macauley, H. Selection of cowpea genotypes in hydroponics, pots, and field for drought tolerance. Crop Sci. 2003, 43, 1114-1120. [CrossRef]

14. Molders, K.; Quinet, M.; Decat, J.; Secco, B.; Dulière, E.; Pieters, S.; van der Kooij, T.; Lutts, S.; Van Der Straeten, D. Selection and hydroponic growth of potato cultivars for bioregenerative life support systems. Adv. Space Res. 2012, 50, 156-165. [CrossRef]

15. Won, J.-H.; Gangwon Provincial, A.; Jeong, B.; Gangwon Provincial, A.; Kim, J.; Jeon, S.; Gangwon Provincial, A. Selection of suitable cultivars for the hydroponics of sweet pepper (Capsicum annuum L.) in the alpine area in summer. J. Bio-Environ. Control 2009, 18, 425-430.

16. Navarro, J.; Garrido, C.; Carvajal, M.; Martinez, V. Yield and fruit quality of pepper plants under sulphate and chloride salinity. J. Hortic. Sci. Biotechnol. 2002, 77, 52-57. [CrossRef]

17. Cerkauskas, R.F. Etiology and management of Fusarium crown and root rot (Fusarium oxysporum) on greenhouse pepper in Ontario, Canada. Can. J. Plant Pathol. 2017, 39, 121-132. [CrossRef]

18. Singh, H.; Dunn, B.; Payton, M. Hydroponic $\mathrm{pH}$ modifiers affect plant growth and nutrient content in leafy greens. J. Hortic. Res. 2019, in press.

19. Brewer, M.; Lang, L.; Fujimura, K.; Dujmovic, N.; Gray, S.; van der Knaap, E. Development of a controlled vocabulary and software application to analyze fruit shape variation in tomato and other plant species. Plant Physiol. 2006, 141, 15-25. [CrossRef]

20. SAS Institute. Base SAS 9.4 Procedures Guide: Statistical Procedures; SAS Institute: Cary, NC, USA, 2017.

21. Flores, R.A.; Borges, B.; Almeida, H.; Prado, R. Growth and nutritional disorders of eggplant cultivated in nutrients solutions with suppressed macronutrients. J. Plant Nutr. 2015, 38, 1097-1109. [CrossRef] 
22. Rubio, J.; García-Sánchez, F.; Flores, P.; Navarro, J.; Martínez, V. Yield and fruit quality of sweet pepper in response to fertilisation with $\mathrm{Ca}^{2+}$ and $\mathrm{K}^{+}$. Span. J. Agric. Res. 2010, 8, 170-177. [CrossRef]

23. Gul, A.; Tuzel, Y.; Tuzel, I.; Irget, M.; Kidoglu, F.; Tepecik, M. Effects of nutrition and irrigation on sweet pepper production in volcanic tuff. Span. J. Agric. Res. 2011, 9, 221-229. [CrossRef]

24. Urrestarazu, M.; Mazuela, P. Effect of slow-release oxygen supply by fertigation on horticultural crops under soilless culture. Sci. Hortic. 2005, 106, 484-490. [CrossRef]

25. Savvas, D.; Leneti, H.; Mantzos, N.; Kakarantza, L.; Barouchas, P. Effects of enhanced ammonium N supply and concomitant changes in the concentrations of other nutrients needed for ion balance on the growth, yield, and nutrient status of eggplants grown on rockwool. J. Hortic. Sci. Biotechnol. 2010, 85, 355-361. [CrossRef]

26. Savvas, D.; Ntatsi, G.; Passam, H. Plant nutrition and physiological disorders in greenhouse grown tomato, pepper and eggplant. Eur. J. Plant Sci. Biotechnol. 2008, 2, 45-61.

27. De Kreij, C.; Başar, H. Leaf tip yellowing in eggplant is caused by boron deficiency. J. Plant Nutr. 1997, 20, 47-53. [CrossRef]

28. Gruda, N. Increasing sustainability of growing media constituents and stand-alone substrates in soilless culture systems. Agronomy 2019, 9, 298. [CrossRef]

29. Rouphael, Y.; Colla, G.; Battistelli, A.; Moscatello, S.; Proietti, S.; Rea, E. Yield, water requirement, nutrient uptake and fruit quality of zucchini squash grown in soil and closed soilless culture. J. Hortic. Sci. Biotechnol. 2004, 79, 423-430. [CrossRef]

30. Dorai, M.; Papadopoulos, A.; Gosselin, A. Influence of electric conductivity management on greenhouse tomato yield and fruit quality. Agronomie 2001, 21,367-383. [CrossRef]

31. Moazed, H.; Ghaemi, A.; Rafiee, M. Evaluation of several reference evapotranspiration methods: A comparative study of greenhouse and outdoor conditions. Iran. J. Sci. Technol. 2014, 38, 421.

32. Savvas, D.; Adamidis, K. Automated management of nutrient solutions based on target electrical conductivity, $\mathrm{pH}$, and nutrient concentration ratios. J. Plant Nutr. 1999, 22, 1415-1432. [CrossRef]

33. Lee, J.Y.; Rahman, A.; Azam, H.; Kim, H.S.; Kwon, M. Characterizing nutrient uptake kinetics for efficient crop production during Solanum lycopersicum var. cerasiforme Alef. growth in a closed indoor hydroponic system. PLoS ONE 2017, 12, e0177041. [CrossRef]

34. Swearengin, L.; Dunn, B.; Singh, H.; Goad, C. Evaluation of a mobile phone plant nitrogen recommendation application in the greenhouse. J. Plant Nutr. 2018, 41, 2615-2625. [CrossRef] 